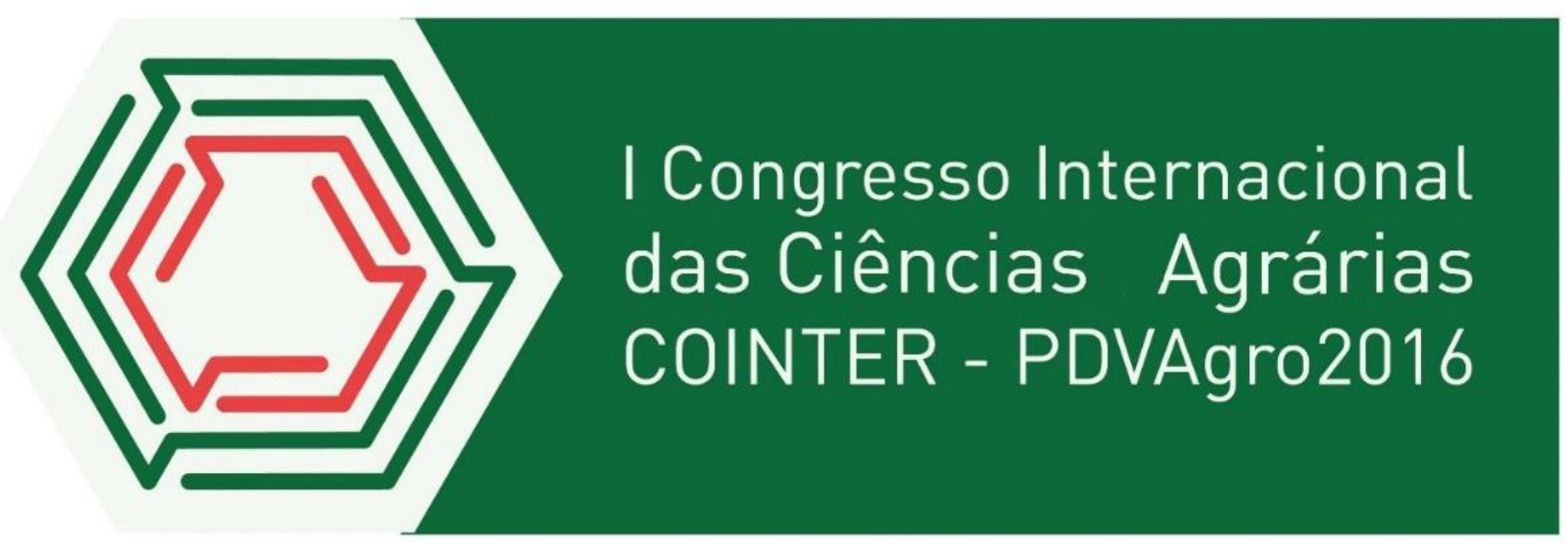

\title{
AVALIAÇÃO DOS SÓLIDOS SOLÚVEIS TOTAIS DO FRUTO DA VIDEIRA ISABEL EM FUNÇÃO DA APLICAÇÃO DE BIOFERTILIZANTES
}

\author{
Apresentação: Pôster
}

\begin{abstract}
Alex Serafim ${ }^{1}$; Jéssica Mota ${ }^{2} ;{ }^{3}$ Joicy Maria; Jackson Mesquita ${ }^{4}$ José Geraldo $^{5}$
\end{abstract}
\section{Introdução}

A videira (Vitis sp.) é considerada uma das primeiras plantas cultivadas pelo homem, juntamente com o trigo, a oliveira, a ervilha, o linho, etc. As principais espécies de videiras cultivadas são a Vitis vinifera, espécie mais freqüente na Europa e utilizada na fabricação de vinhos finos, a $V$. labrusca, a V. rotundifolia, a Vitis riparia e a Vitis aestivalis, todas americanas e utilizadas como porta-enxertos, para produção de uvas de mesa, consumo in natura, sucos, geléias e vinhos (MELLO, 2011).

As uvas americanas (Vitis labrusca L.) são apreciadas para o consumo "in natura" e usadas para a produção de sucos, vinhos de mesa e na confeitaria em geral (RIZZON, MIELE e MENEGUZZO, 2000), sendo amplamente cultivadas no Brasil e de grande importância no consumo interno (RIZZON e MIELE, 2000).

A utilização de resíduos orgânicos de origem animal ou vegetal na adubação das culturas, como estercos, húmus de minhocas, restos de culturas e biofertilizantes, tem melhorado a fertilidade

\footnotetext{
${ }^{1}$ Ciências Agrárias, Universidade Estadual Da Paraíba, alexcdf10@hotmail.com

${ }^{2}$ Ciências Agrárias, Universidade Estadual Da Paraíba, motta.jessica@ymail.com

${ }^{3}$ Ciências Agrárias, Universidade Estadual Da Paraíba, joicy21mariajp@gmail.com

${ }^{4}$ Ciências Agrárias, Universidade Estadual Da Paraíba, franciscalacerdadasilva@hotmail.com

${ }^{5}$ Prof. Dr. Sc. Universidade Estadual da Paraíba, josegeraldo@uepb.edu.br
} 
dos solos, através do aumento da quantidade de matéria orgânica, além de propiciar a produção de alimentos saudáveis (GUERRA et al., 2007).

\section{Fundamentação Teórica}

Nos dias atuais há uma extrema preocupação com a produção e o consume de Frutíferas, uma das mais consumidas é a videira, sendo que o uso de defensivos químicos têm sido muito utilizada, acarretando em problemas tanto ambientais quanto na saúde humana, e o uso de biofertilizantes neste tipo de cultura como nas demais têm sido muito discutido, e assim surge esta dúvida, como o uso de fertilizantes orgânicos pode contribuir na produção saudável e natural destes tipos de frutíferas e qual o desempenho nos tipos e aplicações.

A agricultura de subsistência é uma das práticas que as famílias do campo possui, sendo que para se sustentar a agricultura familiar demonstra necessidade extrema em defensivos químicos, o desconhecimento do homem do campo em se conscientizar em relação as consequências do uso exagerado que os mesmos acarretam, o uso de biofertilizantes quebra este paradigma de que o agricultor não consegue sobreviver sem os produtos químicos, sendo assim a produção de frutíferas como a videira, necessitam de cuidados e nutrição e adubação para uma melhor produção, sendo assim é preciso preservar o nosso solo e ao mesmo tempo usufruir de seus benefícios, por isso queremos demonstrar que a agricultura orgânica é de extrema importância e totalmente necessária para as culturas, com o objetivo de avaliar os sólidos solúveis totais ( Brix $^{\circ}$ ) videira Isabel por meio do uso de biofertilizantes, avaliando sua eficiência por meio de diferentes dosagens;

\section{Metodologia}

A pesquisa com a videira Isabel foi conduzida, no período de fevereiro de 2011 a dezembro de 2015, no Centro de Ciências Humanas e Agrárias - CCHA, da Universidade Estadual da Paraíba UEPB, Campus-IV, distando $2 \mathrm{~km}$ da sede do município de Catolé do Rocha-PB, que está situado na região semiárida brasileira, no Estado da Paraíba.

O delineamento experimental adotado na implantação da pesquisa foi o de blocos casualizados, com 40 tratamentos, no esquema fatorial 5x8, com quatro repetições, totalizando 160 
plantas experimentais. Foram estudados os efeitos de 5 tipos $\left(\mathrm{B}_{1}=\right.$ à base de esterco bovino não enriquecido, $\mathrm{B}_{2}=$ à base de esterco bovino enriquecido com farinha de rocha $\mathrm{MB} 4, \mathrm{~B}_{3}=$ à base de esterco bovino enriquecido com farinha de rocha MB4 e leguminosa (Vigna unguiculata L. Walp.), $\mathrm{B}_{4}=$ à base de esterco bovino enriquecido com farinha de rocha MB4 e cinza de madeira e $\mathrm{B}_{5}=\mathrm{à}$ base de esterco bovino enriquecido com farinha de rocha MB4, leguminosa e cinza de madeira) e de 8 doses de biofertilizante $\left(\mathrm{D}_{1}=0 ; \mathrm{D}_{2}=0,35 ; \mathrm{D}_{3}=0,7 ; \mathrm{D}_{4}=1,05 ; \mathrm{D}_{5}=1,4 ; \mathrm{D}_{6}=1,75 ; \mathrm{D}_{7}=2,1 ; \mathrm{e} \mathrm{D}_{8}\right.$ = 2,45 L/planta/vez), aplicadas a cada 2 meses, na produção e na qualidade da polpa do fruto da videira Isabel.

As adubações de cobertura foram realizadas de dois em dois meses, sendo utilizados os tipos e as doses de biofertilizante preconizadas no projeto em questão. cujo os atributos químicos consta na tabela 1. Os biofertilizantes foram produzidos, de forma anaeróbia, em recipientes plásticos (biodigestores), com capacidade individual para 240 litros, contendo uma mangueira ligada a uma garrafa plástica com água para retirada do gás metano produzido pela fermentação do material através de bactérias. Os biodigestores foram mantidos hermeticamente fechados durante trinta e cinco dias, em média. Em seguida, foram separadas as partes sólida e líquida do biofertilizante.

Tabela 1 Atributos químicos dos biofertilizantes utilizados na pesquisa.

\begin{tabular}{lccccc}
\hline \multirow{2}{*}{ Especificação } & \multicolumn{5}{c}{ Tipos de Biofertilizante } \\
\cline { 2 - 6 } & B1 & B2 & B3 & B4 & B5 \\
\hline pH & 4,68 & 5,15 & 4,94 & 5,09 & 5,25 \\
CE - dS m & & 5,70 & 5,54 & 6,81 & 7,10 \\
Fósforo $\left(\mathrm{mg} \mathrm{dm}^{-3}\right)$ & 296,2 & 338,8 & 388,2 & 394,3 & 403,4 \\
Sódio $\left(\mathrm{cmol}_{\mathrm{c}} \mathrm{dm}^{-3}\right)$ & 1,14 & 0,99 & 0,95 & 1,14 & 1,22 \\
Potássio $\left(\mathrm{cmol}_{\mathrm{c}} \mathrm{dm}^{-3}\right)$ & 0,71 & 0,58 & 0,68 & 1,42 & 1,78 \\
Cálcio $\left(\mathrm{cmol}_{\mathrm{c}} \mathrm{dm}^{-3}\right)$ & 3,75 & 5,75 & 6,00 & 5,10 & 6,00 \\
Magnésio $\left(\mathrm{cmol}_{\mathrm{c}} \mathrm{dm}^{-3}\right)$ & 3,30 & 6,50 & 4,10 & 6,65 & 5,40 \\
Nitrogênio $\left(\mathrm{g} \mathrm{kg}^{-1}\right)$ & 1,00 & 0,80 & 0,80 & 0,70 & 0,80 \\
Enxofre $\left(\mathrm{mg} \mathrm{dm}^{-3}\right)$ & 14,45 & 22,51 & 38,53 & 65,94 & 57,42 \\
\hline
\end{tabular}


A videira foi irrigada através do sistema localizado denominado "Bubller", desenvolvido pela Universidade do Arizona (USA), sendo a condução da água feita através de canos e mangueiras utilizando-se a ação da gravidade. A água foi deslocada através de canos de PVC de $50 \mathrm{~mm}$ e de mangueiras de 1/2 polegada, espaçadas de 2,5 metros, além de mangueiras de $6 \mathrm{~mm}$ para a saída da água. As irrigações foram feitas diariamente, sendo as quantidades de água aplicadas calculadas com base na evaporação do tanque classe $\mathrm{A}$, repondo-se no dia seguinte o volume correspondente à evaporação do dia anterior. O volume de água diário foi aplicado em microbacias niveladas construídas ao redor do caule, com diâmetro de $1 \mathrm{~m}$, possibilitando uma distribuição uniforme da água no sistema radicular da planta.

A operação de colheita da uva foi feita quando os cachos atingiam o ponto de maturação, sendo acondicionados em embalagens apropriadas. Para as análises da polpa da uva, os frutos foram passados em liquidificador, sendo o material colocado em sacos plásticos e acondicionado em geladeira.

Os resultados referentes aos sólidos solúveis foram determinados de acordo com as Normas Analíticas do Instituto Adolfo Lutz (1985). O teor de sólidos solúveis totais ( ${ }^{\circ}$ Brix) foi determinado através de leitura direta em refratômetro, com correção de temperatura, com base em tabela contida no manual do Instituto Adolfo Lutz (1985).

Os efeitos de diferentes tipos e doses de biofertilizante sobre os sólidos solúveis totais foram avaliados através de métodos normais de análise de variância (Teste F), utilizando-se o modelo polinomial (FERREIRA, 2000), enquanto que o confronto de médias foi feito pelo teste de Tukey, utilizando-se o programa estatístico SISVAR para realização das análises estatísticas.

\section{Resultados e discussão}

As análises estatísticas não revelaram efeitos significativos de tipos e de dosagens de biofertilizante, pelo teste $\mathrm{F}$, sobre os sólidos solúveis totais ( ${ }^{\circ}$ Brix). Para a referida variável, a interação dose versus tipo não apresentou significância estatística, indicando que as dosagens de biofertilizante se comportaram de maneira semelhante dentro dos tipos e vice-versa.

Os efeitos não significativos das doses de biofertilizante sobre os sólidos solúveis totais ( $\left.{ }^{\circ} \mathrm{Brix}\right)$ do fruto da videira Isabel podem ser verificados na Figura 1A. Observa-se que as médias variaram de 18,4 a 19,7 ${ }^{\circ}$ Brix, não tendo havido tendências de aumento e diminuição decorrentes das dosagens de 
biofertilizante aplicadas. Com relação aos efeitos dos tipos de biofertilizante (Figura 1B), observa-se que os valores de ${ }^{\circ}$ Brix foram muito aproximados nos tipos $\mathrm{B}_{1}, \mathrm{~B}_{2}$ e $\mathrm{B}_{3}$, variando de 18,6 a $18,9^{\circ} \mathrm{Brix}$, no entanto, houve uma tendência de aumentos nos tipos $\mathrm{B}_{4}$ e $\mathrm{B}_{5}$, embora de forma não significativa, cujos valores giraram em torno de 19,7 ${ }^{\circ}$ Brix. Os valores obtidos na referida pesquisa se aproximam de 18,2 e 18,5 ${ }^{\circ}$ Brix, obtidos por Rombaldi et al. (2004) em cultivo da videira Isabel, em sistemas de produção convencional e alternativo, respectivamente.

Figura 1. Evolução do ${ }^{\circ}$ Brix do fruto da videira Isabel ( $1^{\mathrm{a}}$ colheita $)$ em função de dosagens (A) e tipos (B) de biofertilizante.
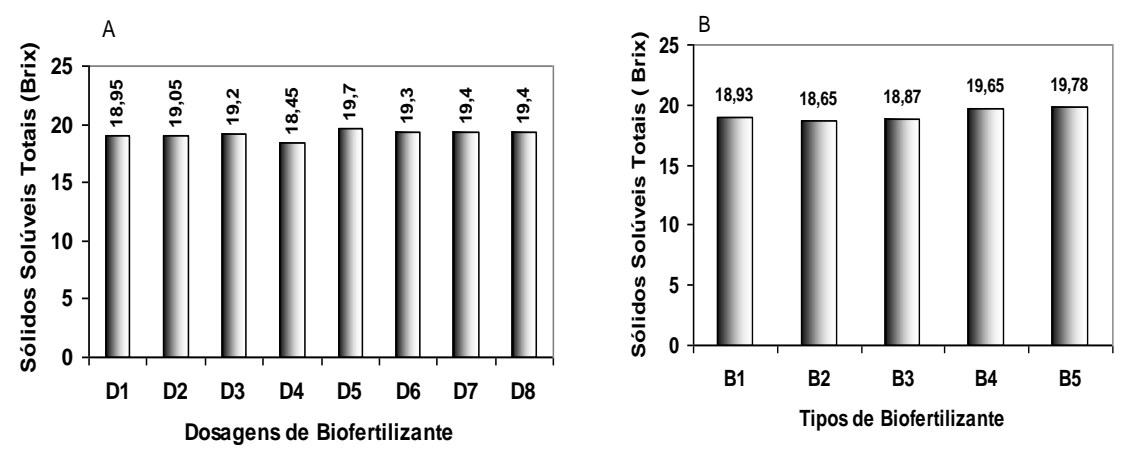

\section{Conclusões}

Os tipos e as dosagens de biofertilizante não afetaram de forma significativa os sólidos solúveis totais $\left({ }^{\circ}\right.$ Brix) do fruto da videira Isabel.

\section{Referências}

FERREIRA, P. V. Estatística experimental aplicada à agronomia. 3 ed. Maceió: UFA1, 2000. 604 p.

GUERRA, J. G. M.; NIDIAYE, A.; ASSIS, R. L. de; ESPINDOLA, J. A. A. Uso de plantas de cobertura na valorização de processos ecológicos em sistemas orgânicos de produção na região serrana fluminense. Revista Agricultura, Piracicaba, v.4, p.1-28, 2007.

INSTITUTO ADOLFO LUTZ. Métodos físicos e químicos para análises de alimentos. 3 ed. São Paulo: IAL, 1985. 533p.

MELLO, L. M. R. Vitiviniculura brasileira: panorama 2010. Disponível em: <http://www. cnpuv. embrapa. br/publica/artigos/prodvit2010.pdf>. Acesso em: 04 jul. 2011. mercado: São Paulo: 1998.

RIZZON, L. A.; MIELE. A. Efeito da relação das fases líquida e sólida da uva na composição química e na característica sensorial do vinho. Ciência e Tecnologia de Alimentos, Campinas, v.19, n.3, p.91-102, 2000. 
RIZZON, L. A.; MIELE, A.; MENEGUZZO, J. Avaliação da uva cv. Isabel para a elaboração de vinho tinto. Ciência Tecnologia de Alimentos, Campinas, v.20, n.1, p.115-121, 2000.

ROMBALDI, C. V.; BERGAMASQUI, M.; LUCCHETA, L.; ZANUZO, M.; SILVA, J.A. Produtividade e qualidade da uva, cv. Isabel, em dois sistemas de produção. Revista Brasileira de Fruticultura, v. 26, p. 89 - 91, 2004. 